\title{
Microstructural Evolution of Injection Molded Gas and Water Atomized 316L Stainless Steel Powder During Sintering
}

\author{
Ryan P. Koseski, Pavan Suri*, Nicholas B. Earhardt, Randall M. German \\ Center for Innovative Sintered Products, 147, Research West, The Pennsylvania \\ State University, University Park, PA, 16802-6903; Young-Sam Kwon, CetaTech, \\ Inc., TIC 296-3, Seonjin-ri, Sacheon, Kyungnam, 664-953, Korea.
}

\begin{abstract}
The present study investigates the microstructural evolution and densification behavior of water and gas atomized 316L stainless steel powder. Dilatometry and quenching studies were conducted to determine the extent of densification and corresponding microstructural changes. Results indicate that water atomized powder could be sintered to $97 \%$ of theoretical density while gas atomized powders could be sintered to near full density. The difference in the densification behavior is examined in terms of the particle morphology, initial green density and the particle chemistry.
\end{abstract}

\section{INTRODUCTION}

Powder injection molding (PIM) is an attractive process to manufacture complex, near net shaped components. Over $50 \%$ of the injection molded and sintered components are made from stainless steel compositions. Gas or water atomized stainless steel powders, shaped and processed via injection molding can achieve high complexity of part geometry with mechanical and corrosion properties similar or superior to wrought material [1-3]. Studies have shown basic differences between gas atomized stainless steel powders and water atomized stainless steel powders when mixed for injection molding. Typically, gas atomized powders are spherical and pack to higher density, properties of key importance for injection molding applications [4]. However, water atomized powders are economical, and improve final shape retention due to the shape characteristics that are generally less spherical and with a more textured surface [2].

To achieve desirable final material characteristics such as strength, ductility and corrosion resistance, the micro-structural changes during sintering are very important. Densification of austenitic stainless steel proceeds via lattice or volume diffusion especially during the initial and intermediate densification stages [5,6]. Previous investigation on the effect of water and gas atomized powder report higher densification for gas atomized powders above $1350^{\circ} \mathrm{C}$ [7]. The purpose of this study is to evaluate the microstructural evolution and compare the densification characteristics in the gas atomized and water atomized 316L stainless steel. The study enables the identification and use of appropriate numerical models for this material system. 


\section{EXPERIMENTAL}

The particle characteristics and chemistry of the gas and water atomized $316 \mathrm{~L}$ stainless steel powders used in this study are given in Table 1 and Table 2. The powders have similar particle size and particle size distribution. Morphology of the powders, observed using scanning electron microscopy (SEM), are given in Figures 1(a) \& (b). The gas atomized powders are spherical and the water atomized powders are rounded and irregular in shape. The powders were mixed with a wax-polypropylene based binder system and injection molded into "U" shaped green bodies. A schematic drawing of the test parts is shown in Figure 2.

The solids loading for the gas and water atomized powders was 65 and $53 \%$ by volume, respectively. Debinding was conducted in a two-step solvent/thermal operation. The green parts were solvent debound at $60^{\circ} \mathrm{C}$ for 4 hour in heptane, followed by a thermal debinding step at $2^{\circ} \mathrm{C} / \mathrm{min}$ to $500^{\circ} \mathrm{C}$ for 1 hour and presintered at $5^{\circ} \mathrm{C} / \mathrm{min}$ to $900^{\circ} \mathrm{C}$ for one hour in hydrogen $\left(\right.$ dew point $\left.-55^{\circ} \mathrm{C}\right)$.

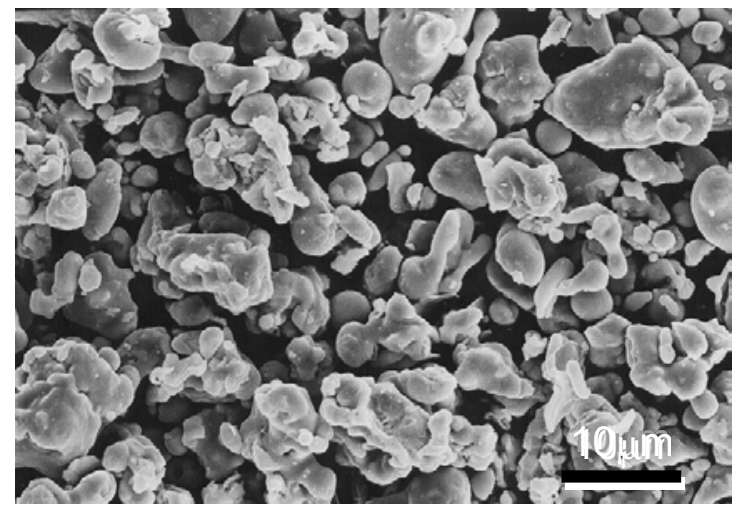

(a)

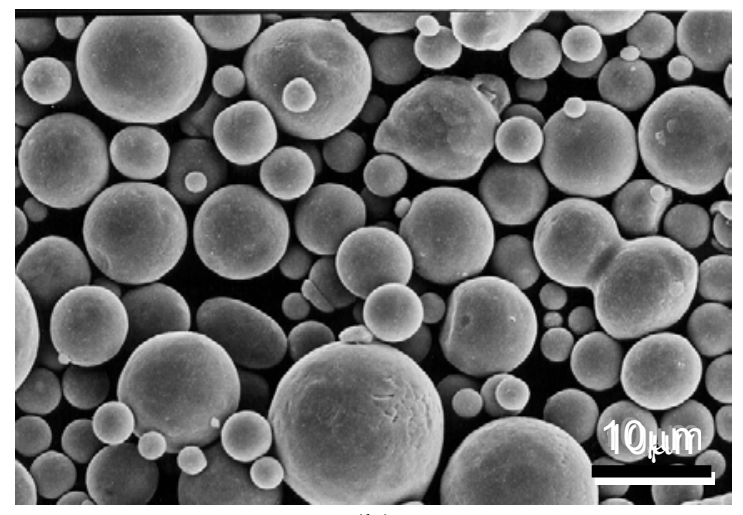

(b)

Figure 1: Scanning electron micrographs of (a) water-atomized and (b) gas atomized 316L stainless steel powders.

The presintered samples were cut into small samples, approximately $1.5 \mathrm{~mm}$ by $1.5 \mathrm{~mm}$ in cross sectional surface area and used for dilatometry and quenching studies. 
Dilatometry was conducted in a vertical push rod dilatometer to quantify the dimensional changes and identify any phase changes in the material as it is sintered. The dilatometer cycle ramped at $10^{\circ} \mathrm{C} / \mathrm{min}$ to $1350^{\circ} \mathrm{C}$ and was held for 1 hour in hydrogen.

Table 1: Particle Characteristic of Stainless Steel Powders

\begin{tabular}{|c|c|c|c|}
\hline \multicolumn{2}{|l|}{ ITEM } & PF-15 & Anval \\
\hline \multicolumn{2}{|l|}{ Vendor } & Pacific Metal Co. & Anval \\
\hline \multicolumn{2}{|l|}{ Production Method } & $\mathrm{W} / \mathrm{A}$ & $\mathrm{G} / \mathrm{A}$ \\
\hline \multicolumn{2}{|l|}{ Shape } & irregular & spherical \\
\hline \multirow{3}{*}{ Particle Size $(\mu \mathrm{m})$} & $\mathrm{D}_{10}$ & 3.7 & 4.6 \\
\hline & $\mathrm{D}_{50}$ & 8.0 & 10.8 \\
\hline & $\mathrm{D}_{90}$ & 14.4 & 18.9 \\
\hline \multicolumn{2}{|c|}{ Width of Distribution $\left(\mathrm{S}_{\mathrm{w}}\right)$} & 4.3 & 4.2 \\
\hline \multicolumn{2}{|c|}{$\begin{array}{l}\text { Tap Density }\left(\mathrm{g} / \mathrm{cm}^{3}\right) \\
\text { Ft (tap/pycno) }\end{array}$} & $\begin{array}{l}3.5 \\
0.45\end{array}$ & $\begin{array}{l}4.8 \\
0.60 \\
\end{array}$ \\
\hline \multicolumn{2}{|c|}{ Pycnometer Density $\left(\mathrm{g} / \mathrm{cm}^{3}\right)$} & 7.93 & 7.96 \\
\hline \multicolumn{2}{|c|}{ Angle of Repose $\left({ }^{\circ}\right)$} & 50 & 45 \\
\hline
\end{tabular}

Table 2: Chemistry of Stainless Steel Powders

\begin{tabular}{|l|l|l|l|l|l|l|l|l|l|l|l|}
\hline (wt.\%) & $\mathrm{Cr}$ & $\mathrm{Ni}$ & $\mathrm{Mo}$ & $\mathrm{Si}$ & $\mathrm{Mn}$ & $\mathrm{Cu}$ & $\mathrm{P}$ & $\mathrm{S}$ & $\mathrm{C}$ & $\mathrm{O}_{2}$ & $\mathrm{Fe}$ \\
\hline PF-15 & 15.7 & 11.3 & 2.07 & 0.86 & 0.09 & 0.03 & 0.028 & 0.002 & 0.019 & 0.35 & bal. \\
\hline ANVAL & 16.3 & 10.3 & 2.26 & 0.53 & 1.50 & 0.28 & 0.017 & 0.005 & 0.025 & 0.09 & bal. \\
\hline
\end{tabular}

Quenching of the sintering components was conducted in a vertical alumina tube furnace. The samples were heated to the desired temperature at $10^{\circ} \mathrm{C} / \mathrm{min}$ and quenched in water. The quenched samples were characterized for their density, dimensional change and subsequently cut into samples and mounted in Bakelite. The densities were determined by Archimedes water immersion method. The mounted samples were plane polished to expose the internal microstructure of the sintered material. Etching was performed with a $2 \% \mathrm{HF}, 8 \% \mathrm{HNO}_{3}, 90 \% \mathrm{H}_{2} \mathrm{O}$ solution at room temperature. The time required to etch varied with the density, with a higher density requiring more time (20 minutes). For samples that required an additional amount or faster etching, a drop of concentrated $\mathrm{HCl}$ was added to the etching solution applied to the surface. Several samples required no etching, as the final polishing step yielded visible and clear grain and pore boundaries. 


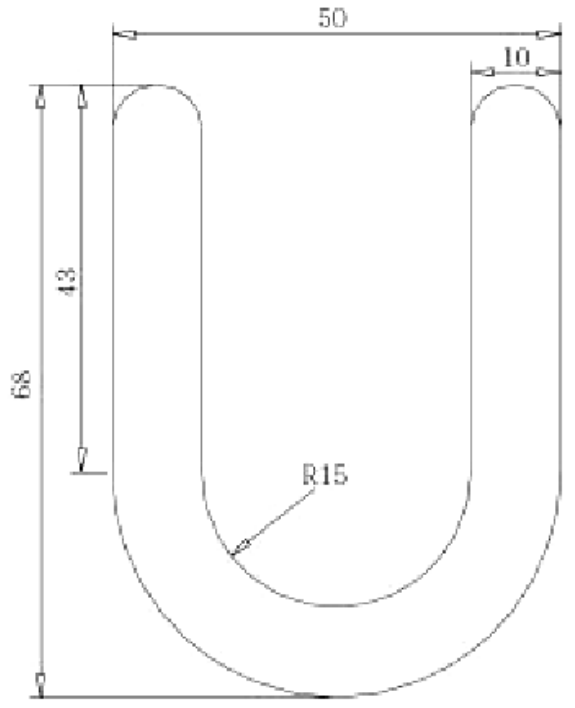

Figure 2: Geometry of Test Sample (3mm depth, all units in $\mathbf{m m}$ )

The grain and pores size data was collected by image analysis on a Clemex® system. Due to twinning and other phenomenon associated with stainless steel, the grain boundaries were required to be identified by the observer. Five images from each quenched temperature were analyzed.

\section{RESULTS}

Figures 3 and 4 show the variation in the sintering shrinkage and shrinkage rate with time. The water atomized sample when sintered to $1350^{\circ} \mathrm{C}$ for one hour in hydrogen exhibits shrinkage of approximately $21 \%$ and was found to be $97 \%$ dense. The density of the gas atomized powder was found to be $99 \%$ with shrinkage of $15 \%$. The lower shrinkage of the gas atomized powder is due to the higher green density of the injection molded compact.

Presintered compacts were heated to $1200^{\circ} \mathrm{C}, 1290^{\circ} \mathrm{C}, 1320^{\circ} \mathrm{C}$, and $1350^{\circ} \mathrm{C}$ at $10^{\circ} \mathrm{C} / \mathrm{min}$ for 0 minutes in hydrogen and quenched in water to observe and evaluate the microstructure of the compacts. The densities of the quenched compacts are given in Table 3. Table 3 also gives a comparison of the densities evaluated from the dilatometry data and microstructural analysis. It can be seen that results from Archimedes density measurements exhibit trends similar to other methods. Further, it can be seen that the relative densities of the water and gas atomized powders are similar up to $1350^{\circ} \mathrm{C} / 0$ minutes after which gas atomized powder sinters to near full density.

The microstructural evolution of the gas atomized powders are given in Figures 4 (a) - (e) and that of water atomized powder are given in Figures 5 (a) - (e). The microstructures show a progression from irregular pores along the particle boundaries to spherical pores within or on the grain boundaries. The figures also indicate poreboundary separation. The microstructural analysis indicates an increase in the grain size 
that is controlled by the pores. It can be seen from Figure 6 that the rate of grain growth increases from $1350^{\circ} \mathrm{C} / 0$ minutes to $1350^{\circ} \mathrm{C} / 60$ minutes due to the annihilation of the pores on the grain boundaries.

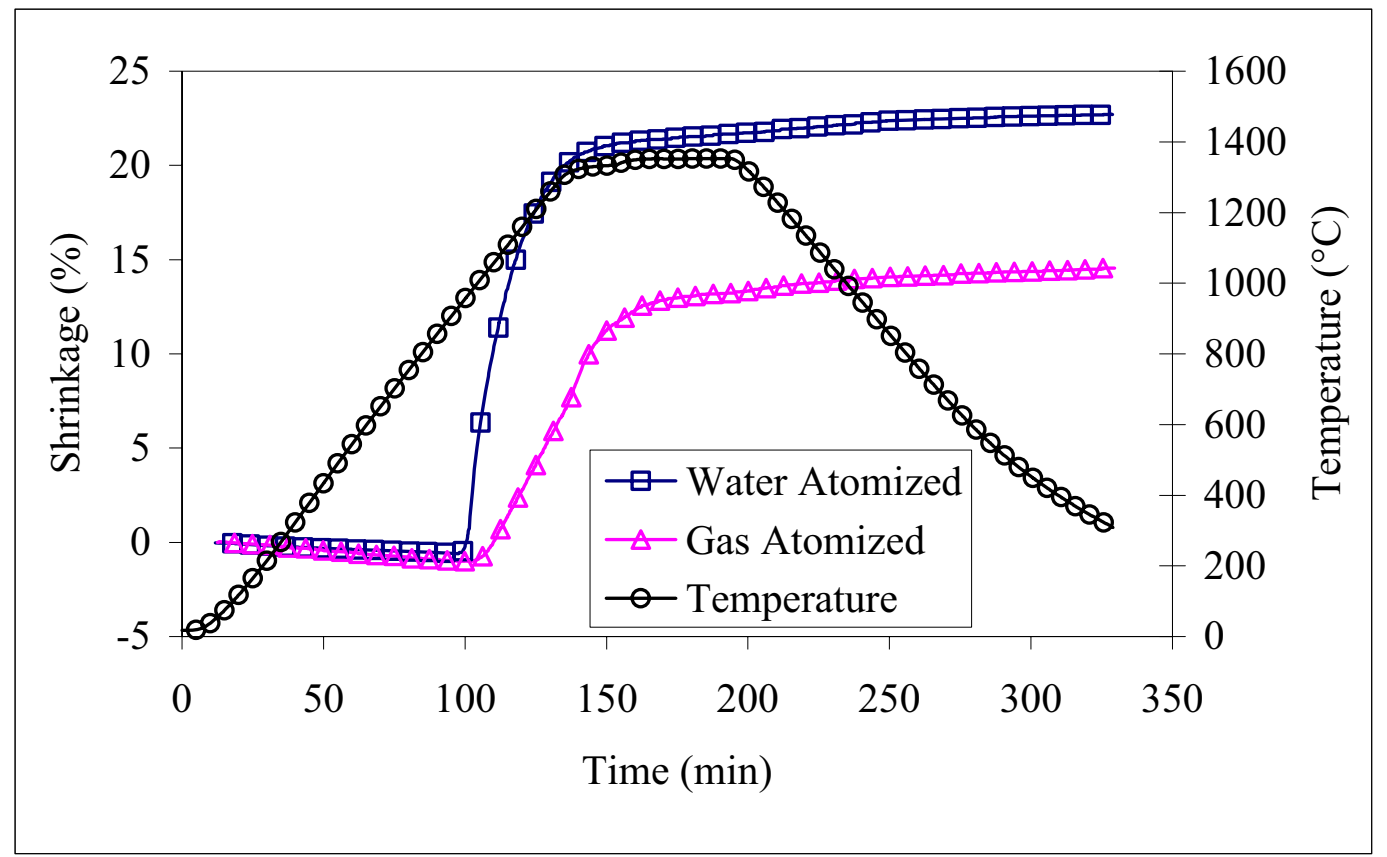

Figure 3: Variation in the shrinkage of the water and gas atomized powders versus time. The samples were sintering at $10^{\circ} \mathrm{C} / \mathrm{min}$ to $1350^{\circ} \mathrm{C}$ for one hour in hydrogen.

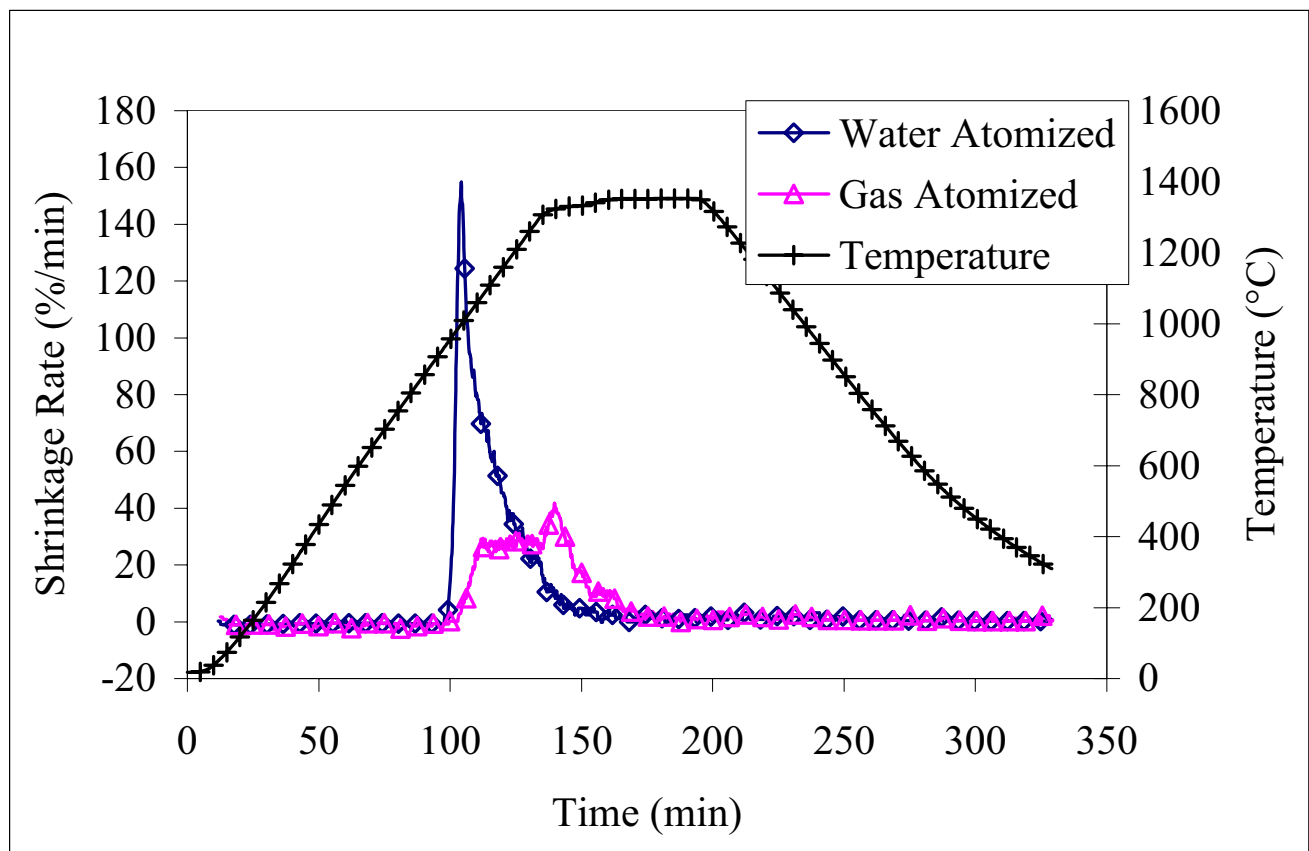

Figure 4: Variation in the shrinkage of the water and gas atomized powders versus time. The samples were sintering at $10^{\circ} \mathrm{C} / \mathrm{min}$ to $1350^{\circ} \mathrm{C}$ for one hour in hydrogen. 
Figure 7 give the variation in the pore area for different sintering conditions. For the case of gas atomized powders, it can be seen that the pores on the grain boundaries coarsen and eventually shrink to result in near full densification. The pores that are trapped with the grain boundaries on the other hand grow continuously with an increase in temperature. For the case of water atomized powder, the size of the pores on the boundaries is smaller compared to the gas atomized powder. Further, the pore size, measured in terms of pore area, increases continuously with an increase in temperature. The increase in the pore size is observed concomitant with a reduction in porosity.

Table 3: Percent sintered density of injection molded compacts at different quench temperatures (note: samples at $1633 \mathrm{~K}$ were held for $1 \mathrm{~h}$ and cooled at $10^{\circ} \mathrm{C} / \mathrm{min}$ to room temperature).

\begin{tabular}{|c|r|c|r|r|r|r|}
\hline Temp (K) & \multicolumn{2}{|c|}{ Water Atomized Powder } & \multicolumn{3}{|c|}{ Gas Atomized Powder } \\
\hline & Quenched & Dilatometry & $\begin{array}{c}\text { Image } \\
\text { Analysis }\end{array}$ & Quenched & Dilatometry & $\begin{array}{c}\text { Image } \\
\text { Analysis }\end{array}$ \\
\hline 1473 & 79.62 & 83.5 & 77.02 & 75.19 & 73.72 & 79.56 \\
\hline 1568 & 87.85 & 91.1 & 84.76 & 81.52 & 80.13 & 77.39 \\
\hline 1593 & 90.63 & 93.25 & 84.19 & 83.04 & 85.21 & 71.37 \\
\hline 1623 & 91.52 & 96.5 & 84.57 & 91.27 & 96.9 & 88.22 \\
\hline 1633 & 97.59 & & 95.59 & 99.87 & & 99.77 \\
\hline
\end{tabular}

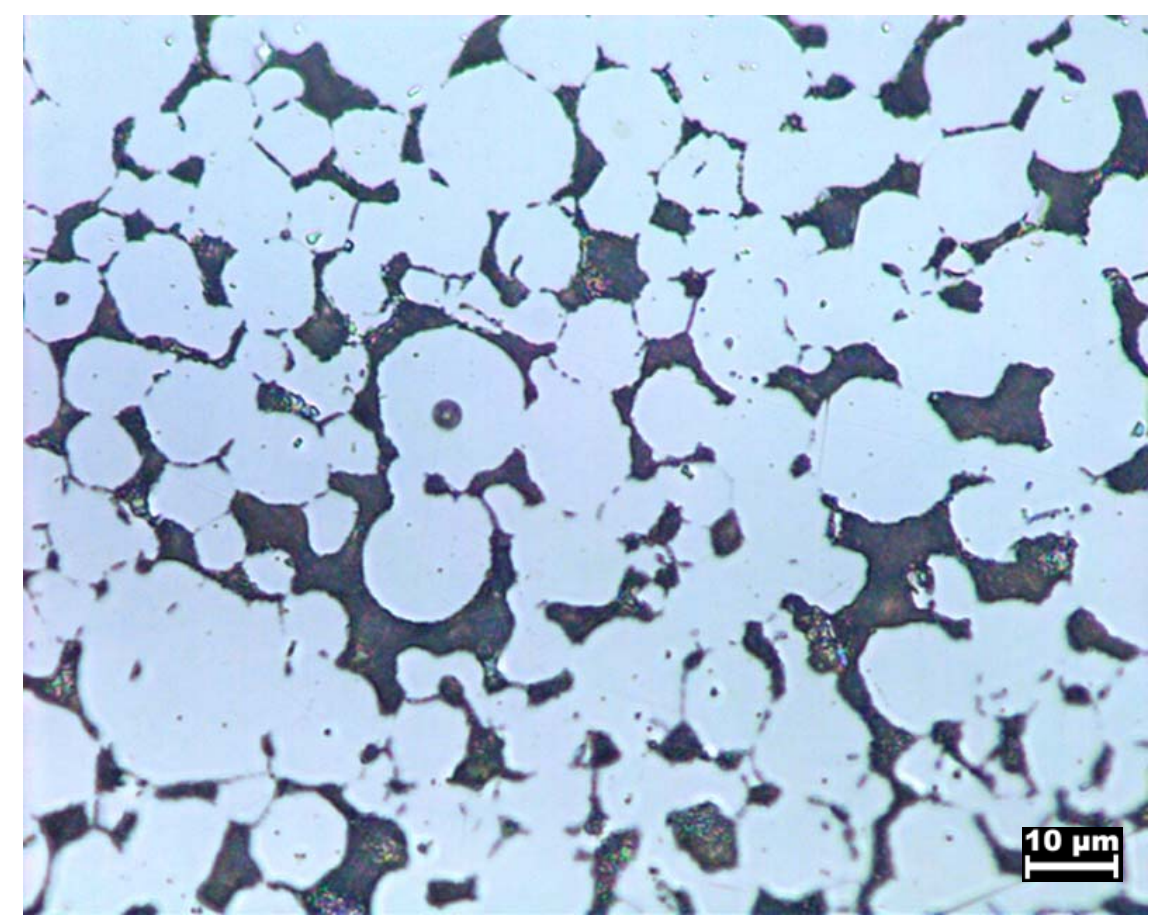

Figure 4 (a): Optical micrograph of gas atomized compact quenched at 1473K. Note that the grains are nearly spherical with most of the pores in between grains and irregular in shape with very few internal pores. 


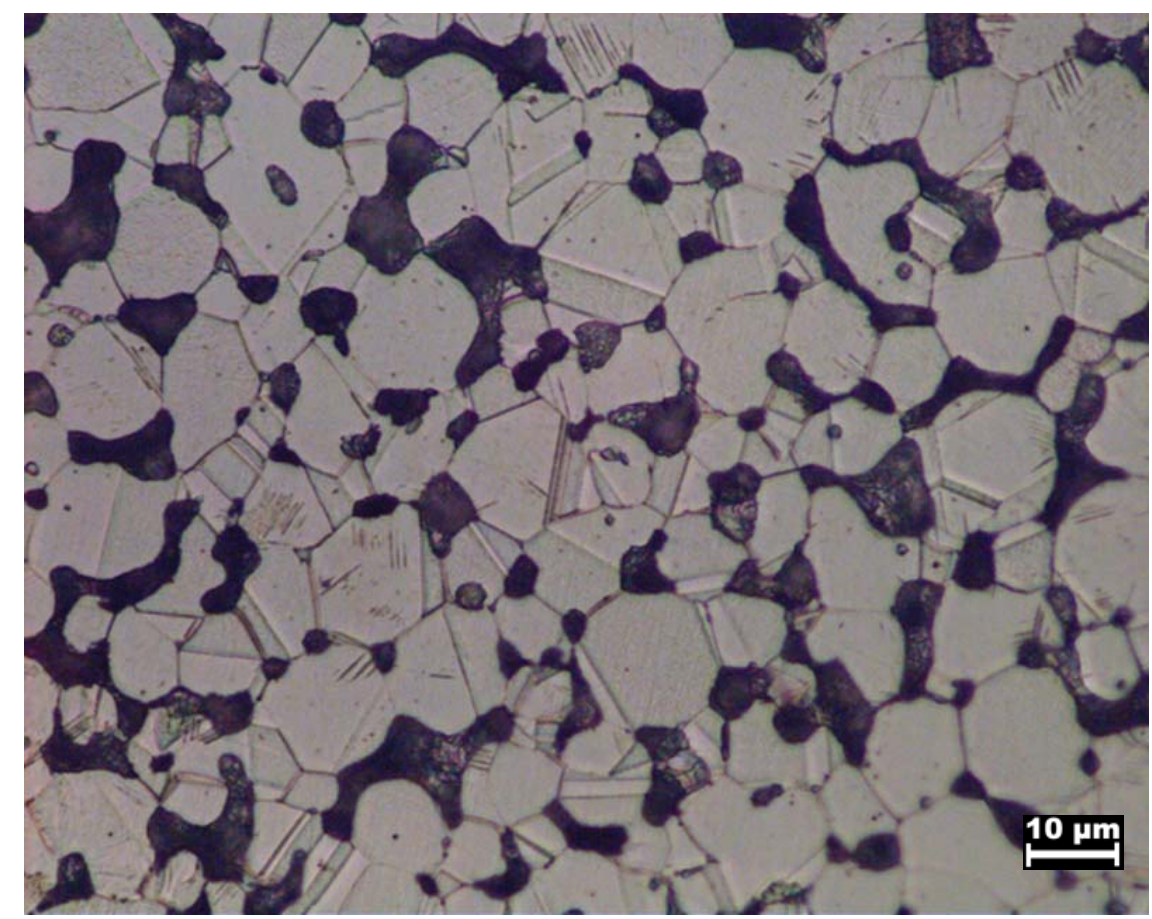

Figure 4 (b): Optical micrograph of the gas atomized compact quenched at $1568 \mathrm{~K}$. Increase in temperature promotes neck growth and change in pore morphology. Irregular and some spherical pores at the grain boundaries as well as a slight increase in spherical internal porosity are observed.

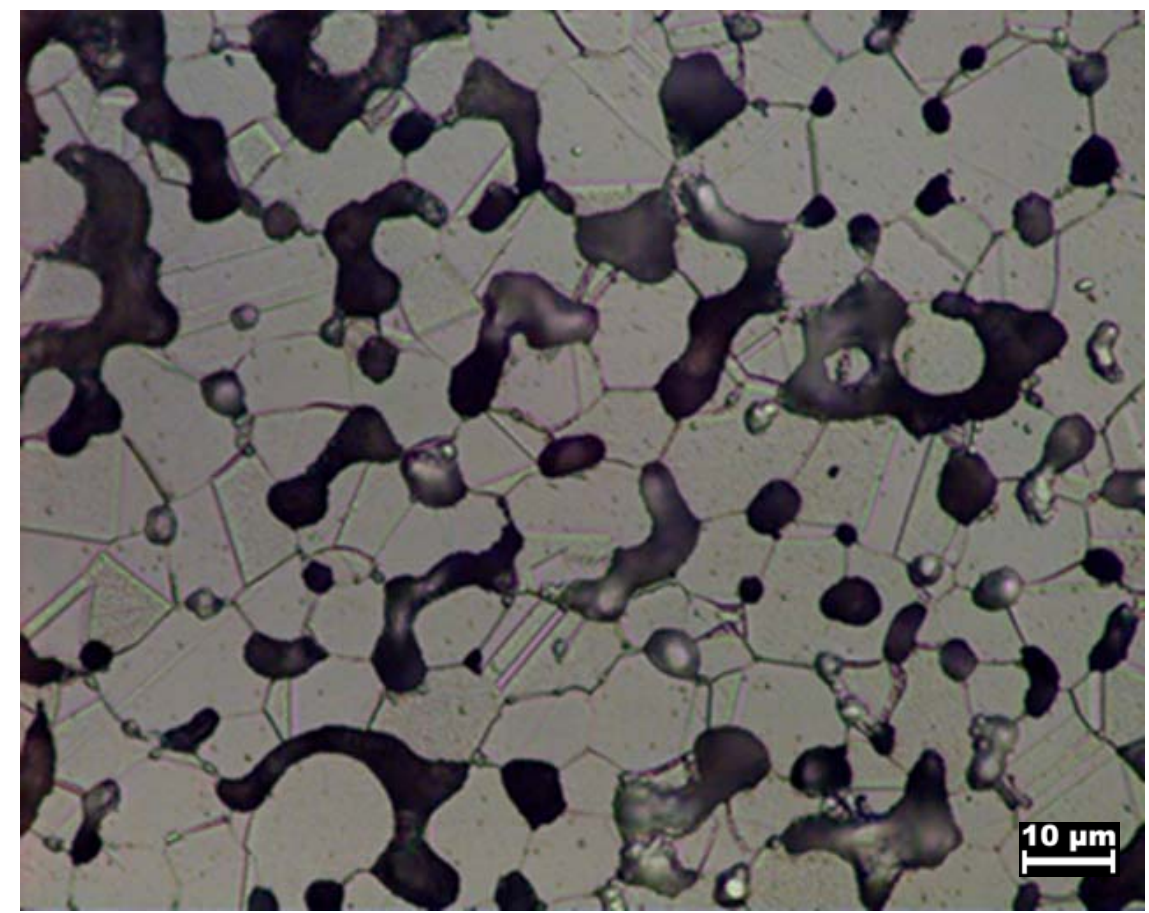

Figure 4 (c): Optical micrograph of the gas atomized compact quenched at $1593 \mathrm{~K}$. The micrograph reveals spherodization of the pores along with pore-boundary separation. 


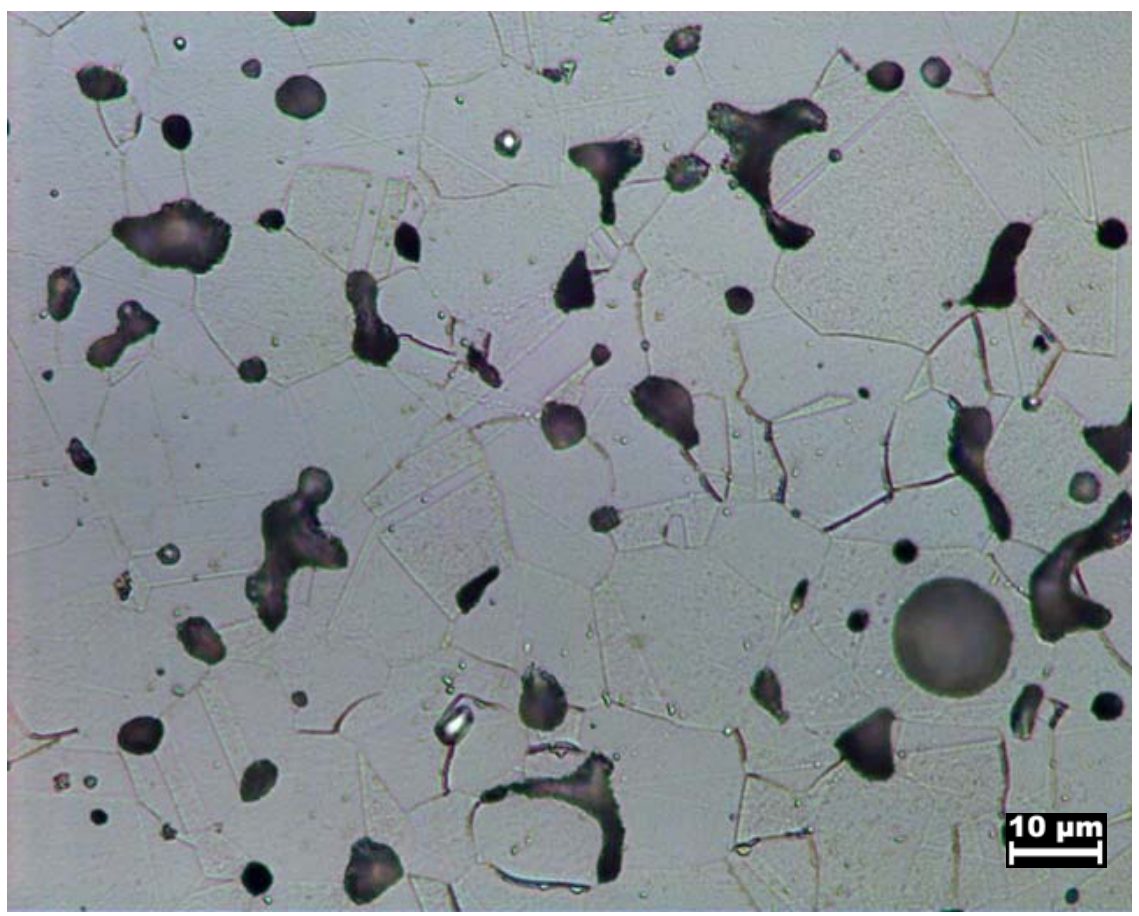

Figure 4 (d): Optical micrograph of the gas atomized compact quenched at $1623 \mathrm{~K}$. The micrograph reveals a decrease in porosity. Some irregular grain boundary pores are seen, as well as internal pores increased in size.

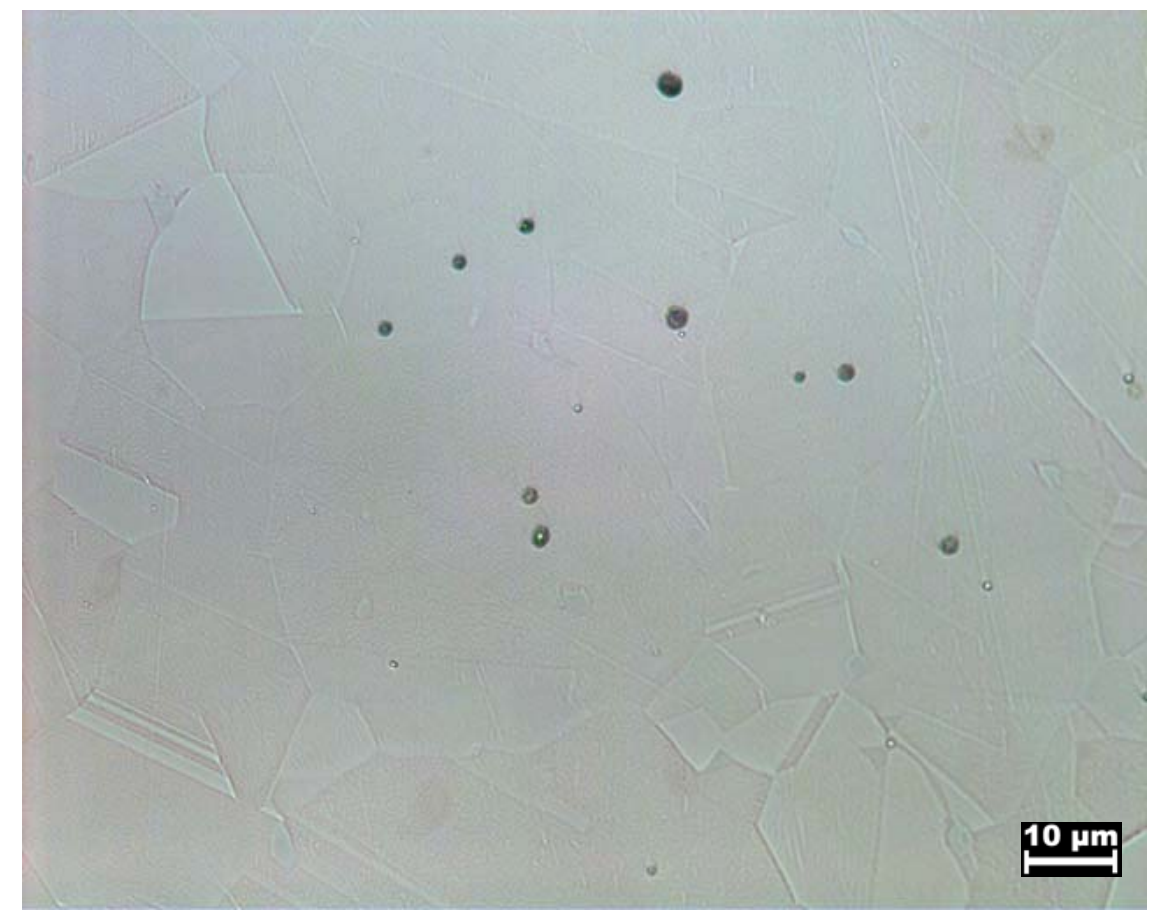

Figure 4 (e): Optical micrograph of the gas atomized compact sintered at 1633K for one hour in hydrogen. Porosity has almost fully disappeared. The grain sizes have increased dramatically. 


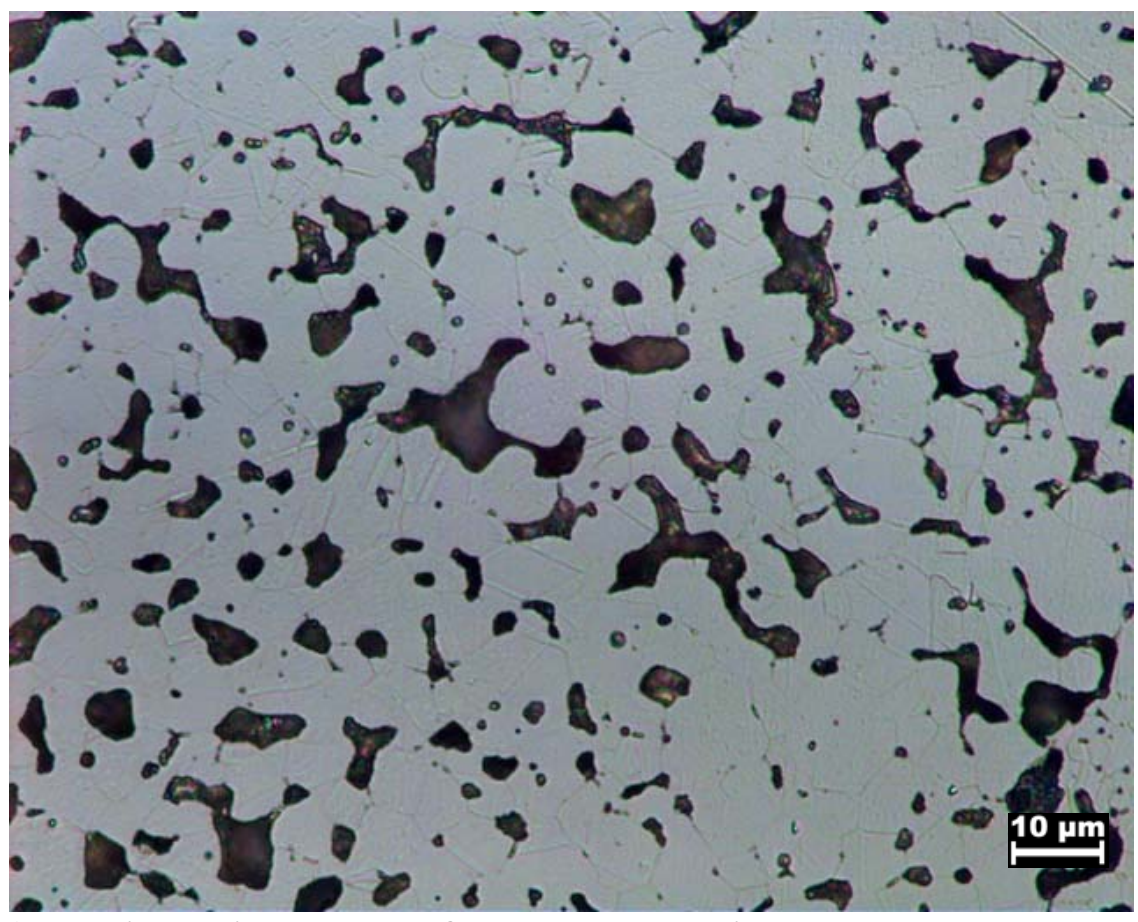

Figure 5 (a): Optical micrograph of the water atomized compact, quenched at 1473K. Pores are almost exclusively on grain boundaries and are irregular in shape.

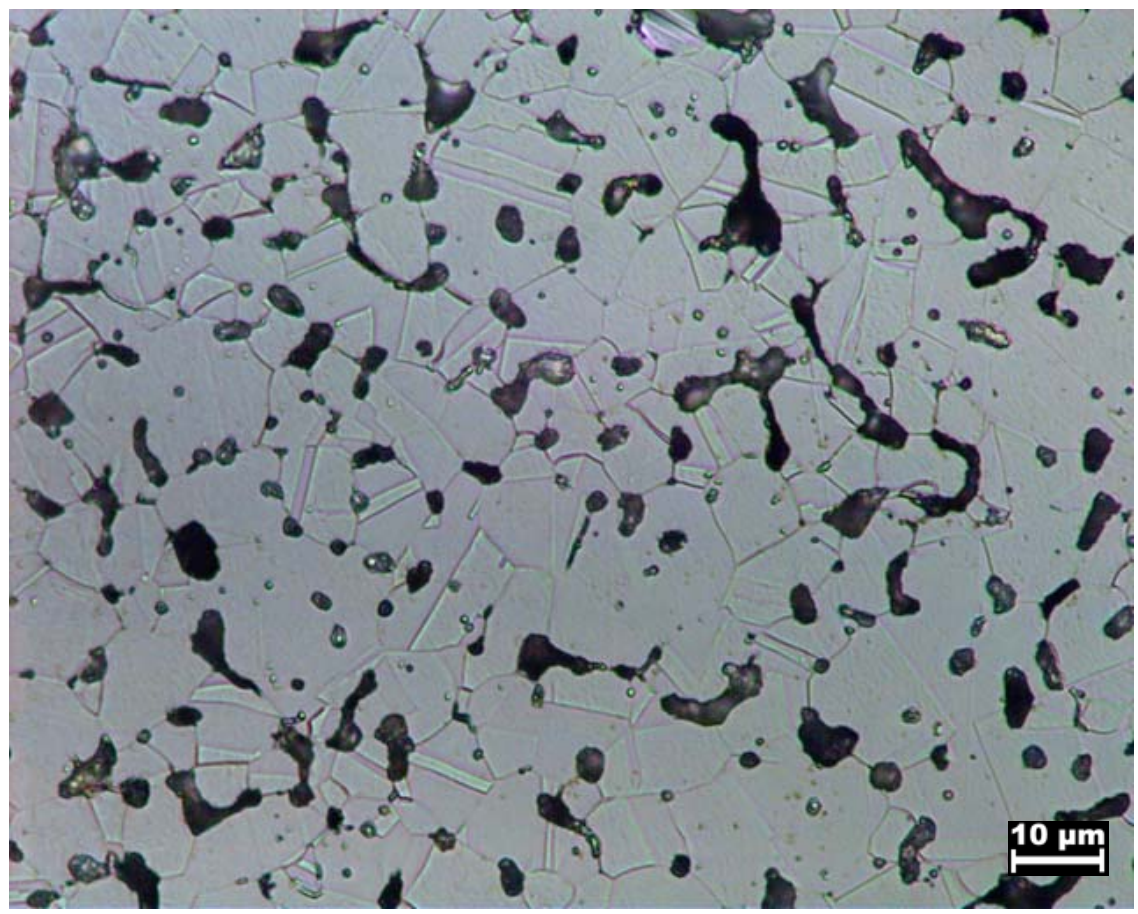

Figure 5 (b): Optical micrograph of the water atomized compact, quenched at $1568 \mathrm{~K}$. Increase in temperature promotes neck growth and change in pore morphology. Irregular and some spherical pores at the grain boundaries as well as a slight increase in spherical internal porosity are observed. 


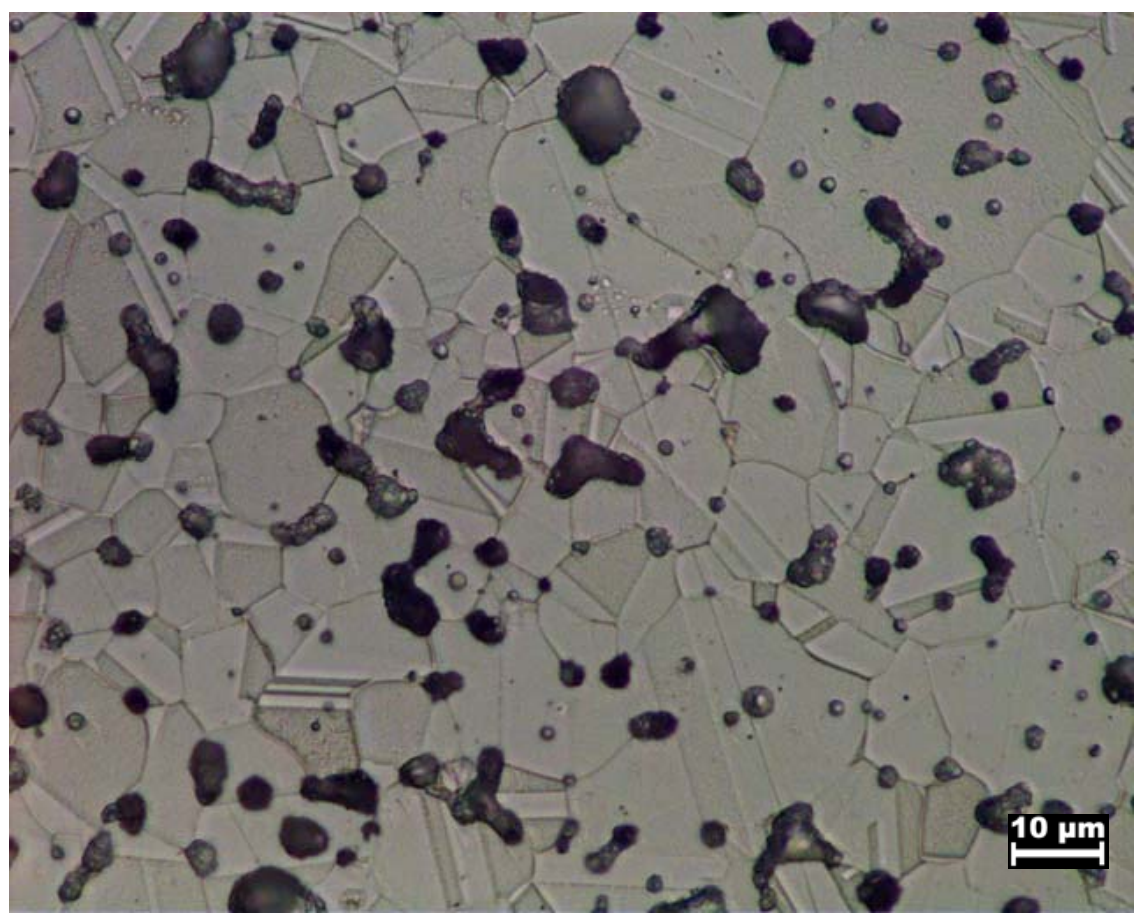

Figure 5 (c): Optical micrograph of the water atomized compact, quenched at 1593K. Grain boundary pores remain irregular, while internal pores are spherical.

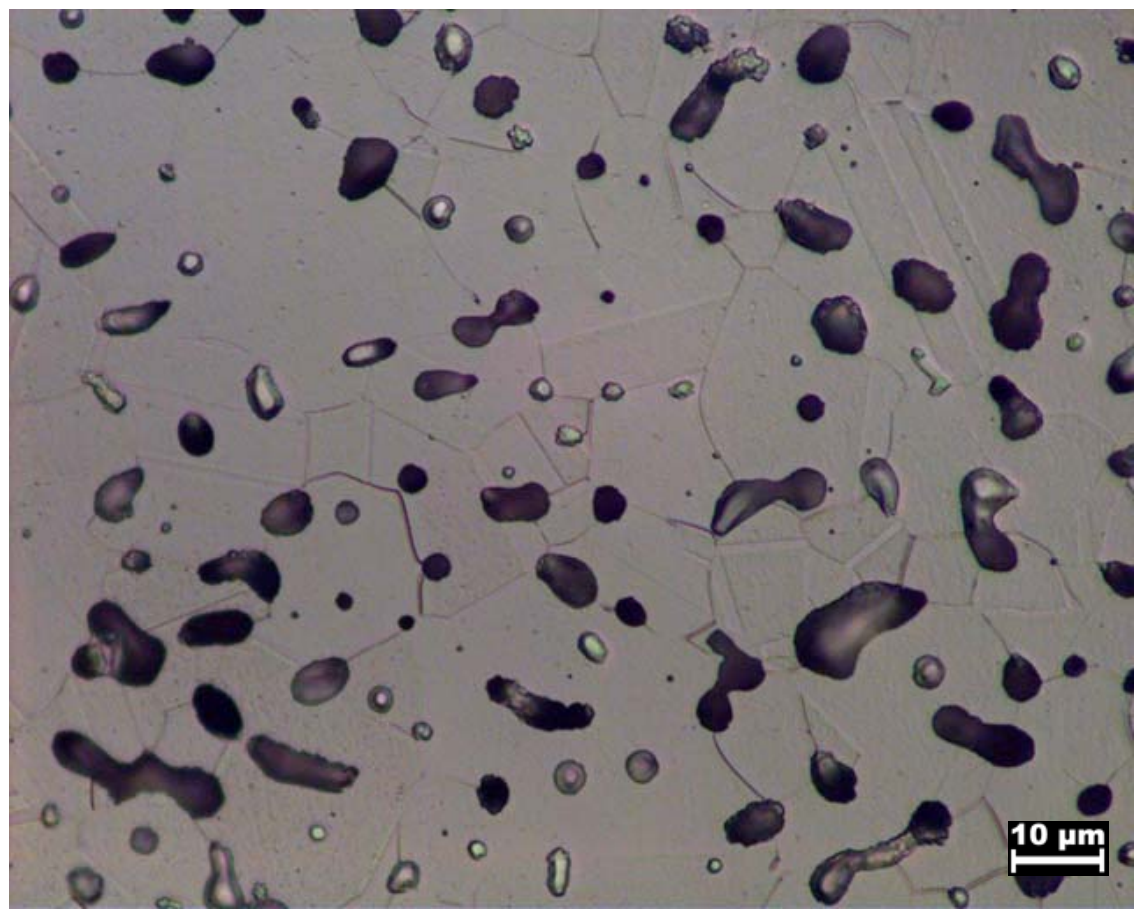

Figure 5 (d): Optical micrograph of the water atomized compact, quenched at $1623 \mathrm{~K}$. Pores become more rounded with an increase in internal porosity. 


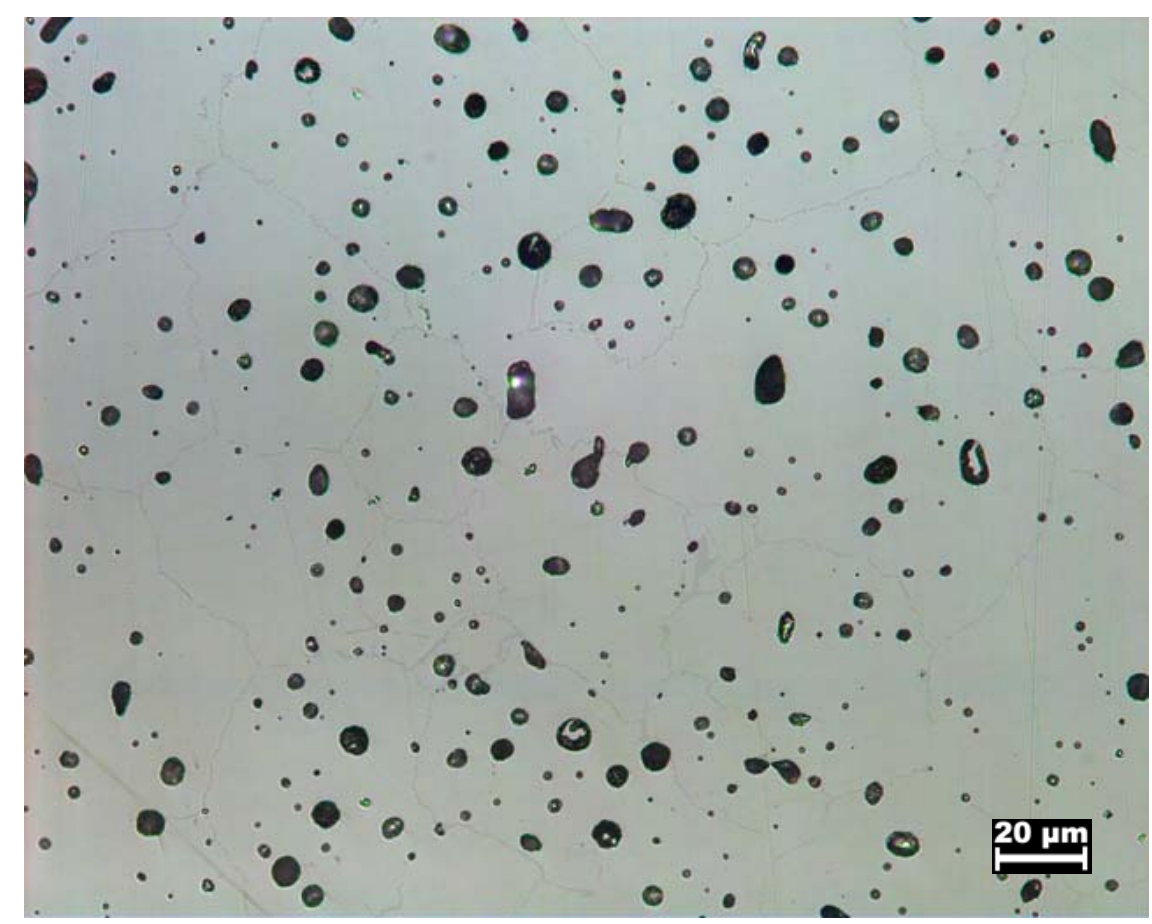

Figure 5 (e): Optical micrograph of the water atomized compact, sintered at $1633 \mathrm{~K}$ for 1 hour in hydrogen and cooled at $10^{\circ} \mathrm{C} / \mathrm{min}$ to room temperature. Pores are rounded and the grain sizes have increased dramatically.

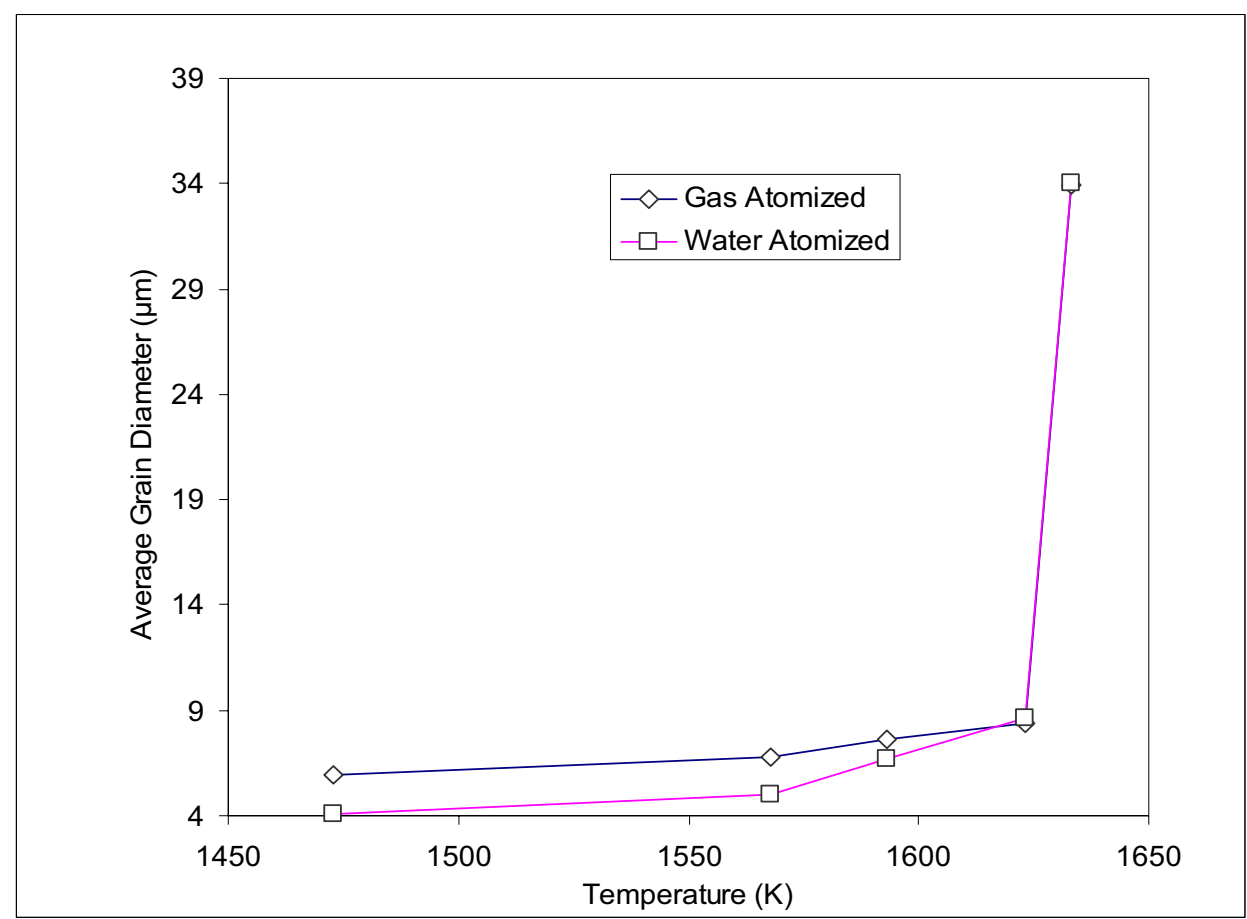

Figure 6: Variation in the average grain size with temperature. Note that the final data point $(1633 \mathrm{~K})$ in both cases were held for 1 hour, while the rest were quenched. The plot clearly establishes a pore controlled grain growth behavior. 


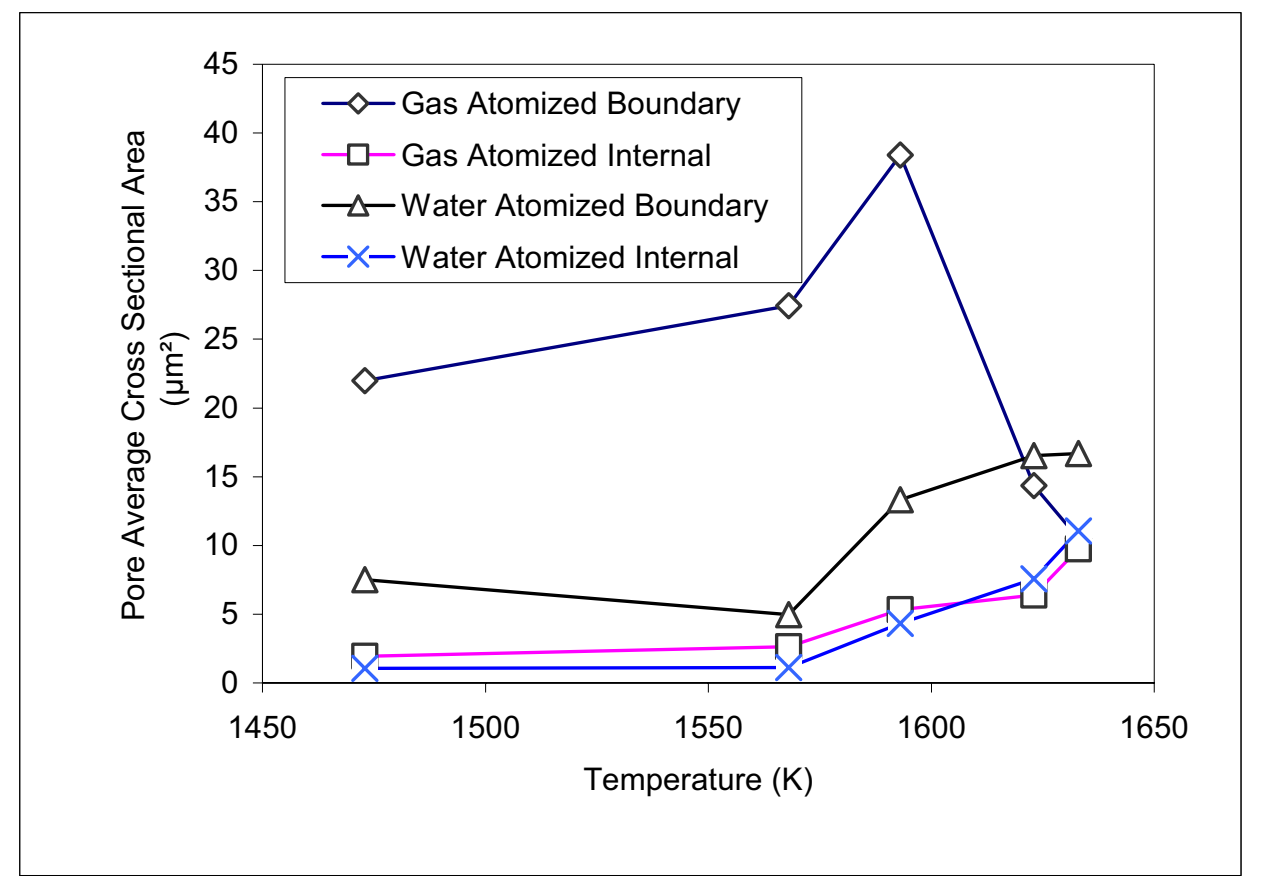

Figure 7: Variation in the average pore area for both grain boundary, and internal pores with temperature. The size of the pores on the grain boundaries of the water atomized powder increases continuously with temperature while pore growth and annihilation is observed for the case of gas atomized powder compact.

\section{DISCUSSION}

It can be seen from Table 1 and Figure 1 that the particle size and distribution of the gas and water atomized powders are very similar. Further, the injection molded compacts are debound and subjected to the same sintering cycle. Hence, differences in the densification behavior is attributable to (a) particle morphology and the resulting green density and (b) particle chemistry.

The irregular morphology of the water atomized stainless steel powder results in very low green density. Poor packing characteristics of this powder is expected to result in a broad pore size distribution that could inhibit sintering [8]. However, particle packing does not seem to have a strong effect on the density evolution of water atomized powder compared to that of the gas atomized powder, as evidenced from the dilatometry, quenching study, or microstructural analysis. Compacts of both powders exhibit similar porosity and grain size. Lower green density of the water atomized powder compact result in a increased sintering rate as seen in Figure 4 and results in a pore size that is smaller that that of gas atomized powder as seen in Figure 7.

Figure 7 indicates pore coarsening and eventual annihilation of the pores on the grain boundaries resulting in near full densification for the gas atomized powder. On the other hand, size of the pores on the grain boundaries is observed to continuously increase for the water atomized powder. In both cases, the average size of the pores trapped 
within the grains increases. Microstructural evolution and analysis indicates pore-grain boundary separation during intermediate stage sintering. Such an observation has not been reported previously but is consistent with the dominant diffusion mechanism and the densification mechanisms. Austenitic stainless steels are determined to undergo densification via lattice (volume) diffusion during the intermediate stage sintering $[5,6]$. During this regime, surface diffusion is also active. Thus, pore migration occurs by a combination of surface and lattice diffusion. At higher temperatures, lattice and grain boundary diffusion contribute to densification. Micrographs suggest that large pores act as vacancy sinks and pin the grain boundary, while small pores separate from the grain boundary and exhibit Oswald ripening type behavior.

Previous reports in comparing the microstructure and properties of the gas and water atomized $316 \mathrm{~L}$ powders do not use particles of similar sizes and attribute presences of oxide layer or evaporation of nickel to the observed differences in densities and microstructures [7]. However, it is unlikely that either of these are the reasons for observed differences in densification behavior. Dilatometry clearly indicates onset and progression of densification between $1000^{\circ} \mathrm{C}-1200^{\circ} \mathrm{C}$, where the oxides (especially $\mathrm{SiO}_{2}$ ) do not reduce [9]. Thus, there is little evidence to suggest that presence of oxides on the prior particle boundaries influence densification. It is rather unlikely to have evaporation events occurring especially in hydrogen atmosphere. The influence of initial pore size distribution also do not seem to have a significant effect - as stated earlier, the size of the pores attached to the grain boundary is higher for the gas atomized powder (that eventually undergoes near full densification) compared to water atomized powder (that exhibits $97 \%$ of the theoretical density when sintered at $1360^{\circ} \mathrm{C} / 1 \mathrm{~h}$ ).

Below $1200^{\circ} \mathrm{C}$ where the reduction of $\mathrm{SiO}_{2}$ is not possible, it can be seen that the water atomized powder undergoes densification and the variation in its grain size is similar to that of the gas atomized powder. This suggests that presence of Si as its oxides does not really hinder either densification of grain growth behavior especially during the initial and intermediate stage sintering. Auger Electron Microscopy studies conducted by Tunberg and Nyborg [9] while studying the sintering of water atomized 304L reveals that $\mathrm{SiO}_{2}$ becomes discontinuous above $1250^{\circ} \mathrm{C}$, and that it is thermodynamically feasible to reduce $\mathrm{SiO}_{2}$ above $1250^{\circ} \mathrm{C}$. Reduction reaction gives rise to $\mathrm{H}_{2} \mathrm{O}$ that should diffuse out. Removal of $\mathrm{H}_{2} \mathrm{O}$ is relatively easy in case of open porosity. However as the compact reaches a closed porosity condition, $\mathrm{H}_{2} \mathrm{O}$ gets trapped within the pore. As the temperature reduces during the cooling cycle, the atmosphere becomes oxidizing [10]. In such an atmosphere, the $\mathrm{SiO}_{2}$ forms again. Oxygen analysis of the sintered compacts revealed $0.196 \mathrm{wt} . \%$ of oxygen in the water atomized powder and $0.0009 \mathrm{wt} . \%$ of oxygen for the gas atomized powder - thus there is a decrease in the oxygen content but is limited due to the closed porosity condition. Nylund et al. also report such results on oxygen content [1]. Thus, it is likely that the trapped $\mathrm{H}_{2} \mathrm{O}$ within the closed pores inhibits and influences the densification behavior of water atomized powder. 


\section{CONCLUSIONS}

Dilatometry and quenching experiments were conducted to evaluate the microstructural evolution and differences in the densification behavior of water and gas atomized 316L stainless steel powder. The water atomized powder could be sintered to $97 \%$ of theoretical density while the gas atomized powder could be sintered to $99 \%$ of theoretical density. The results suggest that:

1. The observed difference in densification behavior could be due to chemistry of the powder rather than the powder morphology. The reduction of oxides (especially $\mathrm{SiO}_{2}$ ) occurs above $1250^{\circ} \mathrm{C}$. However, $\mathrm{H}_{2} \mathrm{O}$, a reduction product gets trapped with the pores as sintering proceeds. Inability of the trapped $\mathrm{H}_{2} \mathrm{O}$ to diffuse out impedes pore annihilations and this alters the densification behavior.

2. Water atomized powder could be sintered to relatively high density despite the low solids loading and initially wide pore size distribution.

\section{ACKNOWLEDGEMENTS}

This investigation was carried as a part of "Sintering Study Group" activity and is supported in part by NASA-GEDS, NSF-REU (Grant \# EEC-0097610), and The Center for Innovative Sintered Products at Penn State.

\section{REFERENCE}

1. A. Nylund, T. Tunberg, H. Bertilsson, E. Carlstrom, and I. Olefjord, The International Journal of Powder Metallurgy, Vol. 31, No.4, 1995, pp.365-373

2. R. M. German and D. Kubish, The International Journal of Powder Metallurgy, Vol. 29, No.1, 1995, pp.47-62

3. L. Cai and R. M. German, The International Journal of Powder Metallurgy, Vol. 31, No.3, 1995, pp.257-264.

4. R.M. German, Powder Injection Molding, 1990, Metal Powder Industries Foundation, Princeton, N.J.

5. T. Pieczonka, J. Kazior, A. Tizani, and A. Molinari, Journal of Materials Processing Technology, Vol. 64, 1997, pp. 327 - 334.

6. R. M. German, Metallurgical Transactions A, Vol. 7A, 1976, pp. 1879-1885.

7. U. Lindstedt and B. Karlsson, Doktorsavhandlingar Vid Chalmers Tekniska Hogskola, No. 1375, 1998, pp. 1 - 25.

8. J. Zhao and M. P. Harmer, Journal of American Ceramic Society, Vol. 71, 1988, pp. 113-120.

9. T. Tunberg and L. Nyborg, Powder Metallurgy, Vol. 38, No. 2, 1995, pp. $120-130$.

10. R. M. German, Sintering Theory and Practice, 1996, John Wiley and Sons, NY, pp. 438-440. 